Article

\title{
Design of Peak Efficiency of 85.3\% WPC/PMA Wireless Power Receiver Using Synchronous Active Rectifier and Multi Feedback Low-Dropout Regulator
}

\author{
Zaffar Hayat Nawaz Khan ${ }^{1}$, Young-Jun Park ${ }^{1}$, Seong Jin Oh ${ }^{1}$, Byeong Gi Jang ${ }^{1}$, \\ Seong-Mun Park ${ }^{1}$, Hamed Abbasizadeh ${ }^{1}$, Young Gun Pu ${ }^{1}$, Keum Cheol Hwang ${ }^{1}$ (i), \\ Youngoo Yang ${ }^{1}$, Minjae Lee ${ }^{2}$ and Kang-Yoon Lee ${ }^{1, *}$ \\ 1 College of Information and Communication Engineering, Sungkyunkwan University, Suwon 16419, Korea; \\ zaffar@skku.edu (Z.H.N.K.); pyj88@skku.edu (Y.-J.P.); geniejazz@skku.edu (S.J.O.); \\ seeys17@skku.edu (B.G.J.); psm7289@skku.edu (S.-M.P.); hamed@skku.edu (H.A.); \\ hara1015@naver.com (Y.G.P.); khwang@skku.edu (K.C.H.); yang09@skku.edu (Y.Y.) \\ 2 School of Information and Communications, Gwangju Institute of Science and Technology, \\ Gwangju 61005, Korea; minjae@gist.ac.kr \\ * Correspondence: klee@skku.edu; Tel.: +82-31-299-4954
}

Received: 20 January 2018; Accepted: 22 February 2018; Published: 25 February 2018

\begin{abstract}
An efficient synchronous active rectifier and Multi Feedback low drop out (LDO) Regulator coupled with a wireless power receiver (WPR) is proposed in this study. An active rectifier with maximum power conversion efficiency (PCE) of $94.2 \%$ is proposed to mitigate the reverse leakage current using zero current sensing. Output voltage and current are regulated by multi-feedback LDO regulator, sharing the single path transistor. The proposed chip is fabricated in the $0.18 \mu \mathrm{m} \mathrm{BCD}$ technology having die area of $16.0 \mathrm{~mm}^{2}$. A $94.2 \%$ power conversion efficiency with the load current of $800 \mathrm{~mA}$ is measured for the proposed active rectifier.
\end{abstract}

Keywords: wireless power receiver; active rectifier; multi-feedback low-dropout regulator; power conversion efficiency (PCE)

\section{Introduction}

Wireless power transfer (WPT) technology is getting significant attention in recent research, especially with mobile phone chargers. Its applications vary from medical components to automobiles [1]. The inductive coupling method is one of the popular WPT methods applicable for a distance below $0.5 \mathrm{~cm}$ with a transfer frequency in the range of $87 \mathrm{kHz}$ to $375 \mathrm{kHz}$. This method is standardized by two consortiums: Wireless Power Consortium (WPC) and the Power Matters Alliance (PMA). Whatever we use the charging technique for, maintaining a high efficiency is necessary which is important because low efficiency will produce heat from the receiver which creates several problems. Under normal conditions, a WPT system has more than $5 \mathrm{~W}$ of power at its input, low efficiency of the receiver causes heat which reduces the receiver efficiency [2-6]. Usually, the whole efficiency of wireless power receiver (WPR) is controlled by the rectifier [7]. As low-dropout (LDO) regulators get their DC supply from the rectifier, rectifier efficiency is crucial. The output voltage of rectifier determines the LDO regulator's efficiency. Protection functions like over current protection (OCP), over voltage protection (OVP), and adaptive communication limit (ACL) are unified with the LDO regulator.

This study proposes an efficient active rectifier and multi-feedback LDO (MF-LDO) regulator coupled with a wireless power receiver. Section 2 describes the architecture and building blocks of inductive coupling WPR. The simulation results are presented in Sections 3 and 4 summarizes the paper. 


\section{Proposed Wireless Power Receiver Design and Its Implementation}

\subsection{Architecture}

The simplified block diagram of the wireless power receiver is depicted in Figure 1 where the power is transmitted to the receiver through the coil. The impedance matching network maximizes the power transfer from the receiving coil to active rectifier. The active rectifier converts the input $\mathrm{AC}$ signals $\left(\mathrm{AC}_{1}\right.$ and $\left.\mathrm{AC}_{2}\right)$ to $\mathrm{DC}$ voltage. The proposed active rectifier uses synchronous control by tracking input frequency by ZCS (zero current sensing) with a monostable circuit to eliminate the double pulse problem. The battery needs regulated DC voltage which is generated by the MF-LDO regulator. Protection functions are integrated to the proposed MF-LDO in this work. A 10-bit ADC converts the internal analog signals from several blocks into digital signals. The digital control block collects them and arranges the packets based on them. To perform the load modulation, it serializes the parallel data into serial data and finally delivers to the modulator. In this work, a complete wireless power receiver (WPR) is designed with proposed active rectifier and MF-LDO.

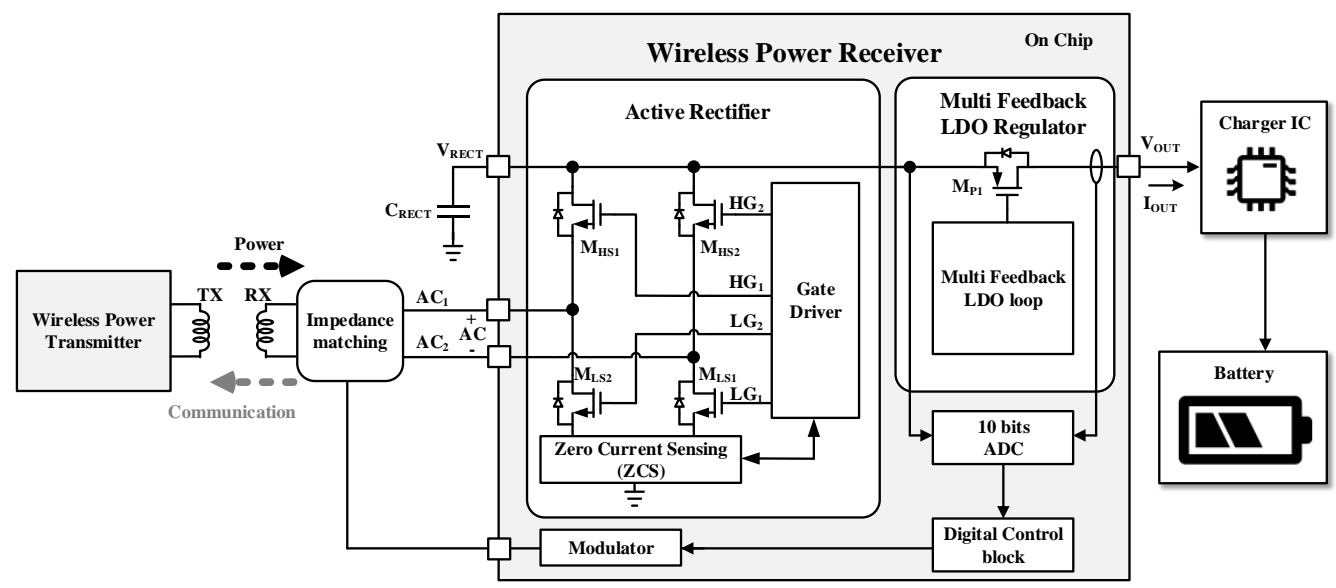

Figure 1. The simplified block diagram of the proposed wireless power receiver.

\subsection{Active Rectifier}

A design of active rectifier is proposed in this work which receives AC input voltage, the polarity of this input voltage decides which metal oxide semiconductor (MOS) transistor will turn on and off actively in the active rectifier, as exhibited in Figure 2. High power conversion efficiency is achieved because, at MOS transistors, less voltage drop can be made as compared to diode-based passive rectifier [8].

$$
\eta_{\text {rectifier }}=\frac{\mathrm{V}_{\text {out }}}{\left|\mathrm{V}_{\text {in }}\right|} \times \frac{\mathrm{I}_{\text {out }}}{\mathrm{I}_{\text {in }}} \approx \frac{\mathrm{V}_{\text {out }}}{\mathrm{V}_{\mathrm{do}}+\mathrm{V}_{\text {out }}} \times \frac{\mathrm{I}_{\text {out }}}{\mathrm{I}_{\text {loss }}+\mathrm{I}_{\text {out }}}
$$

The rectifier efficiency is calculated by Equation (1).

In this equation;

$\mathrm{V}_{\mathrm{do}}=$ Voltage drop in conducting path

$\mathrm{I}_{\text {loss }}=$ Current loss, defined by the reverse current leakage in power stage

As the power transfer begins, the active rectifier operates in passive mode and operates in active mode when $\mathrm{V}_{\text {RECT }}$ gets voltage of the required power level.

The received AC power input rectification power conversion efficiency will be low with high output power level, therefore, the power efficiency of the rectifier is maximized by minimizing $V_{d o}$ [9]. Passive diodes have some forward voltage drop which can limit the efficiency of a rectifier $[8,10,11]$.

On the other hand, MOS transistors have a bidirectional current flow where current flow will be from DC output to AC input. Power conversion efficiency is extremely reduced by this leakage current [12-16]. 


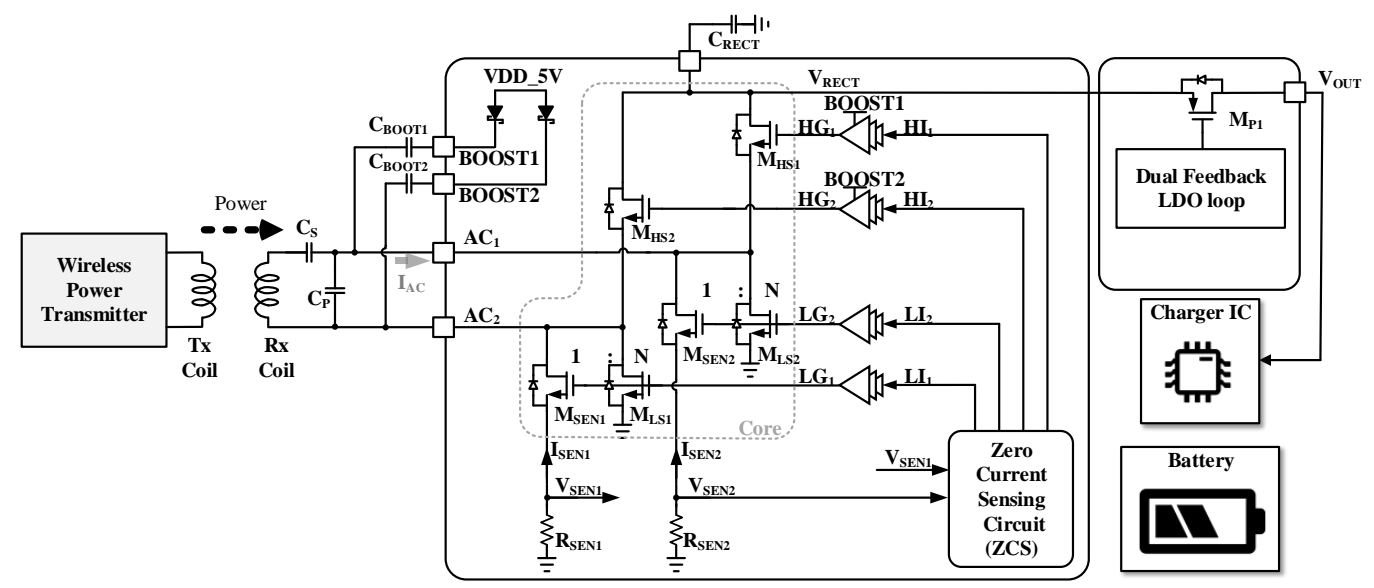

Figure 2. Block diagram of the active rectifier.

In Figure 3, the ZCS circuit senses the current of the active rectifier to prevent the reverse leakage current. To generate the gate signals $\left(\mathrm{LI}_{1}, \mathrm{HI}_{1}\right)$ that turn on and off $\mathrm{M}_{\mathrm{LS} 1}$ and $\mathrm{M}_{\mathrm{HS} 1}$ respectively, the ZCS circuit senses source voltages $\left(\mathrm{V}_{\mathrm{SEN} 1}\right)$ of the sensing MOSFET $\left(\mathrm{M}_{\mathrm{SEN} 1}\right)$. Also, gate control signals of $\mathrm{LI}_{2}$ and $\mathrm{HI}_{2}$ are generated by $\mathrm{M}_{\mathrm{SEN} 2}$ in the same way. The gate control signals $\left(\mathrm{LI}_{1}, \mathrm{HI}_{1}\right)$ are turned and off based on Equations (2) and (3).

$$
\begin{gathered}
\text { Turn - on: } V_{\text {REF1 }} \leq \frac{\left(\text { VDD_5V }-V_{\text {SEN1 }}\right) \times R_{0}}{R_{1}+R_{0}} \\
\text { Turn - off: } V_{\text {REF1 }}>\frac{\left(V D D \_5 V-V_{\text {SEN1 }}\right) \times R_{0}}{R_{1}+R_{0}}
\end{gathered}
$$

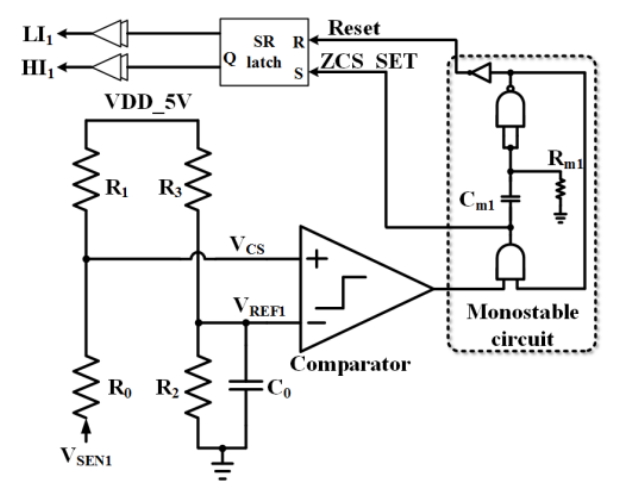

Figure 3. Zero current sensing (ZCS) circuit for $\mathrm{M}_{\mathrm{HS} 1}$ and $\mathrm{M}_{\mathrm{LS} 1}$.

The efficiency of the active rectifier is improved by the ZCS circuits because reverse currents of the active rectifier are prevented. The resistors of $R_{0}, R_{1}, R_{2}$, and $R_{3}$ with a low-temperature variation are used in ZCS circuit. The $V_{R E F 1}$ and $V_{C S}$ voltages are generated by resistive ratio. Therefore, the ZCS circuit is designed strongly against the change in PVT variation. The monostable circuit and SR latch in the ZCS circuits are used to prevent the double pulse problem by glitches in the gate signals $\left(\mathrm{LI}_{1,2}\right.$ and $\left.\mathrm{HI}_{1,2}\right)$.

The timing diagram of the ZCS circuit is shown in Figure 4a. At zero crossing point of ZCS_SET is generated. In Figure 2, power transistors $\left(\mathrm{M}_{\mathrm{HS} 1}, \mathrm{M}_{\mathrm{HS} 2}, \mathrm{M}_{\mathrm{LS} 1}\right.$, and $\left.\mathrm{M}_{\mathrm{LS} 2}\right)$ are turned on by ZCS_SET and turned off by the reset signal. To turn on the high side transistors ( $\mathrm{M}_{\mathrm{HS} 1}$ and $\mathrm{M}_{\mathrm{HS} 2}$ ) with the minimum conduction losses, the bootstrap circuit shown in Figure 2 generates boost voltages $\left(\mathrm{V}_{\mathrm{BST}}\right.$ and $\left.\mathrm{V}_{\mathrm{BST} 2}\right)$ with the amplitude levels of $\mathrm{AC}$ signals $\left(\mathrm{AC}_{1}\right.$ and $\left.\mathrm{AC}_{2}\right)$ plus $5 \mathrm{~V}$ since the maximum gate-source voltages of high side transistors $\left(\mathrm{M}_{\mathrm{HS} 1}\right.$ and $\left.\mathrm{M}_{\mathrm{HS} 2}\right)$ are $5 \mathrm{~V}$ in this process. 
The simulation results of the Active rectifier are shown Figure $4 \mathrm{~b}$. When $\mathrm{I}_{\mathrm{AC}}$ is $20 \mathrm{~mA}$, the $\mathrm{LG}_{1}$ and $\mathrm{HG}_{1}$ are turned on. On the other hand, when the $\mathrm{I}_{\mathrm{AC}}$ is less than $5 \mathrm{~mA}, \mathrm{LG}_{1}$, and $\mathrm{HG}_{1}$ are turned off and the reverse leakage current is blocked.

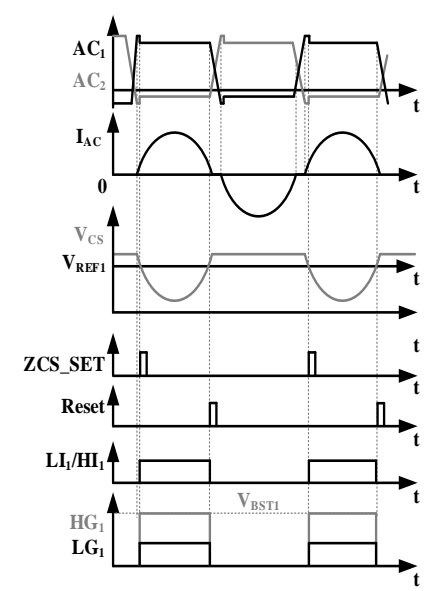

(a)

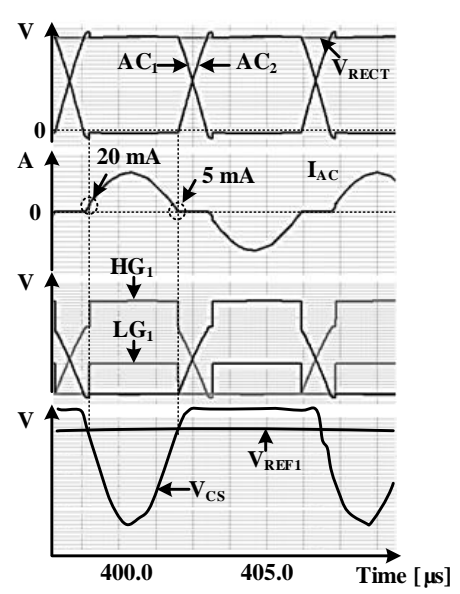

(b)

Figure 4. (a) Timing diagram of the ZCS circuit. (b) Simulation results of the active rectifier.

\subsection{Multi Feedback LDO (MF-LDO) Regulator}

A regulated DC output is provided to the charger IC before the battery and this is provided by the LDO regulator. In the WPR system, the receiver needs various protection functions. In a conventional LDO regulator, the voltage feedback loop is implemented. A MF-LDO regulator is proposed in Figure 5, in which the protection functions are incorporated to low-dropout regulator. The MF-LDO regulator shares the power transistor $\mathrm{M}_{\mathrm{P} 1}$, to save die area.

Figure 6 shows simplified functional diagram of multi feedback LDO. The load current, IOUT, is defined by $V_{G}, V_{R E C T}$, and $V_{O U T}$ voltages. $V_{\text {OUT }}$ and $V_{R E C T}$ voltages are defined by the specification and the active rectifier respectively. Therefore, only $\mathrm{V}_{\mathrm{G}}$ controls the $\mathrm{I}_{\mathrm{OUT}}$, and is derived from Equation (4).

$$
\mathrm{V}_{\mathrm{G}}=\frac{\mathrm{t}}{\mathrm{C}_{\mathrm{G}}} \times\left(\mathrm{I}_{\mathrm{FB}}+\mathrm{I}_{\mathrm{OVP}}+\mathrm{I}_{\mathrm{OCL}}+\mathrm{I}_{\mathrm{ACL}}+\mathrm{I}_{\mathrm{SINK}}\right)
$$

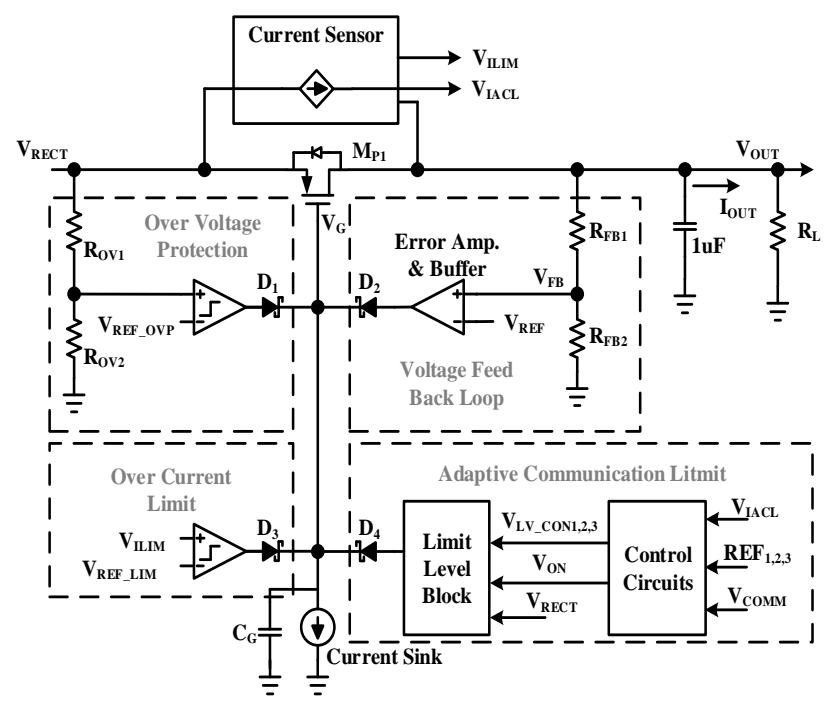

Figure 5. Multi-feedback LDO (MF-LDO) regulator. 
In the normal operation mode of MF-LDO, the $\mathrm{I}_{\mathrm{SINK}}$ current discharges the $\mathrm{V}_{\mathrm{G}}$ node constantly. Also, the $\mathrm{I}_{\mathrm{FB}}$ current is generated by voltage feedback loop. Therefore, $\mathrm{V}_{\mathrm{OUT}}$ voltage is regulated constantly, and the $\mathrm{V}_{\mathrm{G}}$ voltage is changed depending on $\mathrm{I}_{\mathrm{OUT}}$ currents. In the protection modes of MF-LDO-such as OCP, OVP, or ACL modes- $\mathrm{I}_{\mathrm{OCP}}$, $\mathrm{I}_{\mathrm{OVP}}$, and $\mathrm{I}_{\mathrm{ACL}}$ are not zero current sources. When the $\mathrm{I}_{\mathrm{OCP}}, \mathrm{I}_{\mathrm{OVP}}$, and $\mathrm{I}_{\mathrm{ACL}}$ are not zero current sources, $\mathrm{V}_{\mathrm{G}}$ voltage is increased and the $\mathrm{I}_{\mathrm{OUT}}$ current is blocked or limited since the ISINK current is constant.

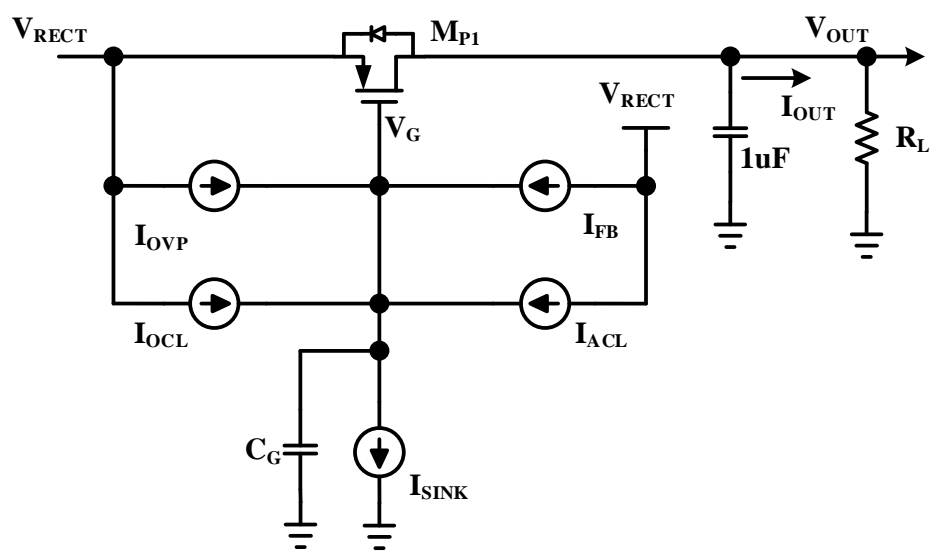

Figure 6. Simplified function diagram of multi-feedback LDO.

Figure 7 shows the adaptive communication limit (ACL) circuit. If the load current (IOUT) increases rapidly during the WPC communication period, communication errors may occur. In order to prevent it, $\mathrm{I}_{\mathrm{OUT}}$ is limited by the ACL circuit. The input signals of control circuits are the $\mathrm{V}_{\mathrm{COMM}}$ signal, the output signal $\left(V_{I A C L}\right)$ of the current sensor, and references $\left(R E F_{1,2,3}\right)$. The $A C L$ is enabled by the $V_{C O M M}$ signal and the current limit level is determined depending on the voltage level of $\mathrm{V}_{\text {IACL }}$ signal. When the $\mathrm{V}_{\mathrm{ON}}$ is high, the parasitic gate capacitor $\left(\mathrm{C}_{\mathrm{G}}\right)$ of $\mathrm{M}_{\mathrm{P} 1}$ is charged by the limit level block through the diode, $\mathrm{D} 4$. Therefore, the voltage level of $\mathrm{V}_{\mathrm{G}}$ is increased, and the output current ( $\mathrm{I}_{\mathrm{OUT}}$ ) is limited.

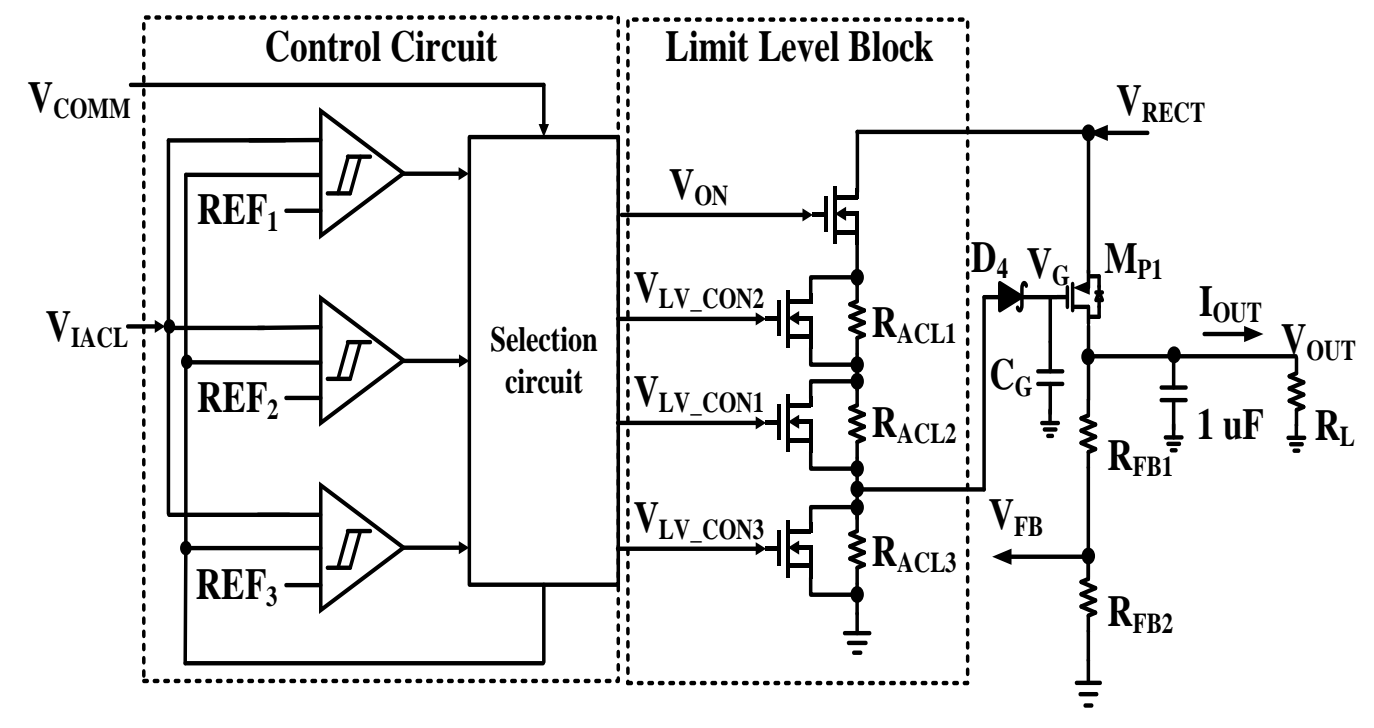

Figure 7. Adaptive communication limit circuit.

Simulated results of a MF-LDO regulator are presented in Figure 8. The MF-LDO regulator regulates the output voltage to $5 \mathrm{~V}$ under the load current of $200 \mathrm{~mA}$. The ACL is enabled at this load current and regulated up to $400 \mathrm{~mA}$. 


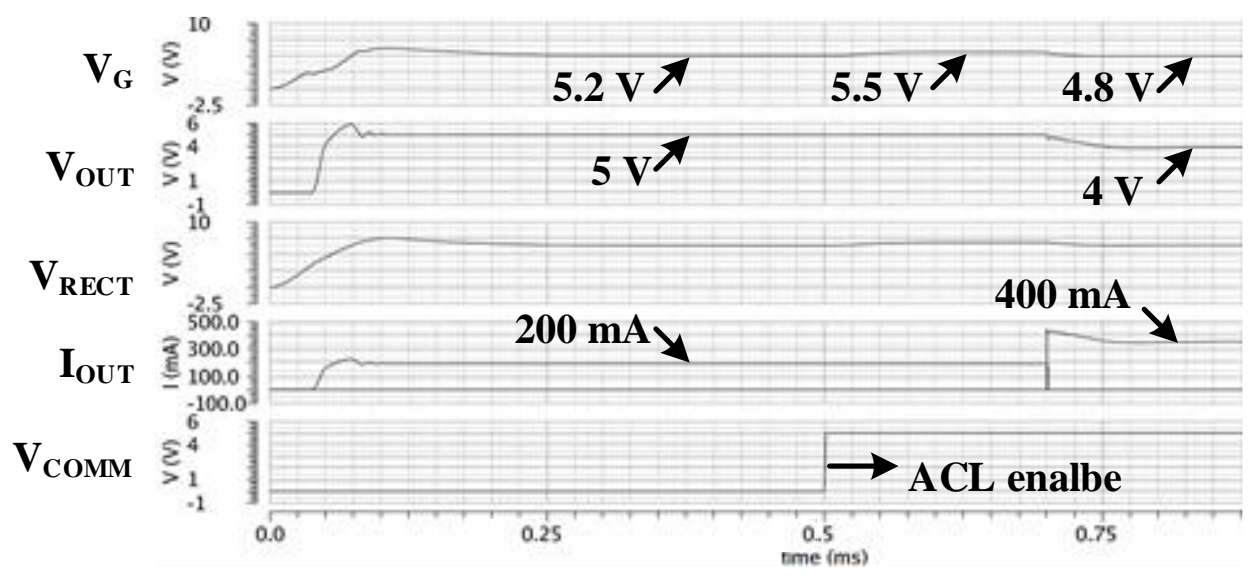

Figure 8. Simulation results of multi-feedback LDO (MF-LDO) regulator.

\section{Experimental Results}

The proposed WPR chip is fabricated in $0.18 \mu \mathrm{m}$ 1P4M with MIM capacitors and high sheet resistance poly resistors. Figure 9 shows the chip layout pattern of the WPR. The die area in the WPR is $16.0 \mathrm{~mm}^{2}$.

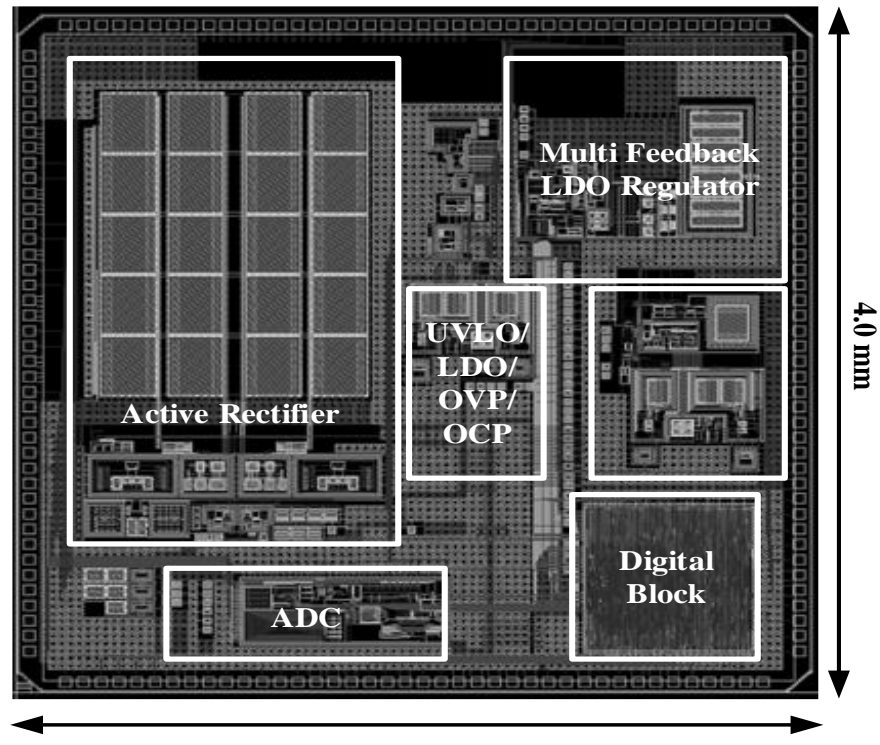

Figure 9. Chip layout pattern.

The measurement environment of wireless power receiver is displayed in Figure 10. Inductive wireless power is generated by power transmitter. Below the receiver coil, a transmitter coil is placed.

The measured waveform of the active rectifier is revealed in Figure 11. The ZCS circuit operates the active rectifier. $\mathrm{M}_{\mathrm{HS} 1}$ and $\mathrm{M}_{\mathrm{LS} 1}$ start to be turned on at $10 \mathrm{~mA}$ current of IAC and are active during the interval time $\mathrm{T} 1$. On the other hand, $\mathrm{M}_{\mathrm{HS} 2}$ and $\mathrm{M}_{\mathrm{LS} 2}$ start to be turned on at $-15 \mathrm{~mA}$ current of $\mathrm{I}_{\mathrm{AC}}$ and are active during the interval time $\mathrm{T} 2$.

The measured waveform of MF-LDO is shown in Figure 12. The value of load current ( $\mathrm{I}_{\mathrm{OUT}}$ ) varies from $200 \mathrm{~mA}$ to $600 \mathrm{~mA}$ to check the performance of MF-LDO. When the MF-LDO is in the normal operation mode, VOUT is regulated to $5.0 \mathrm{~V}$. On the other hand, when the ACL is enabled, IOUT is limited to $450 \mathrm{~mA}$. 


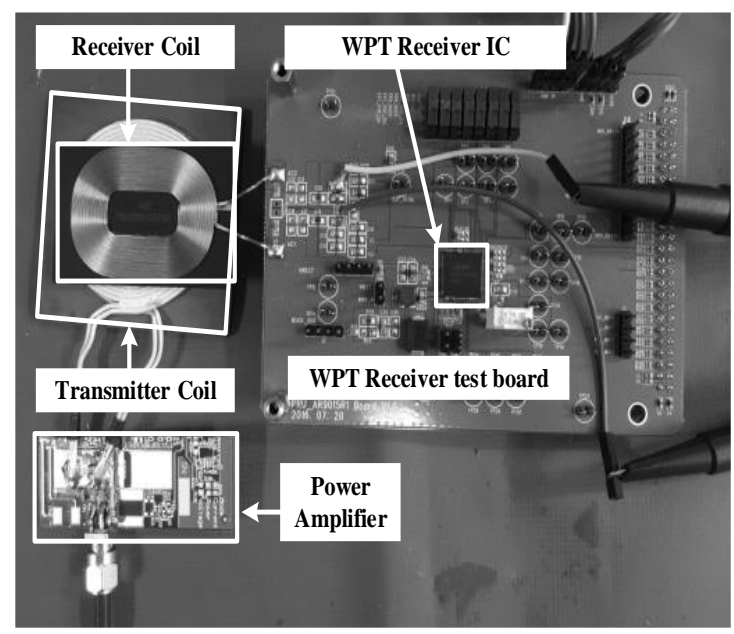

Figure 10. Measurement environment of the wireless power receiver.

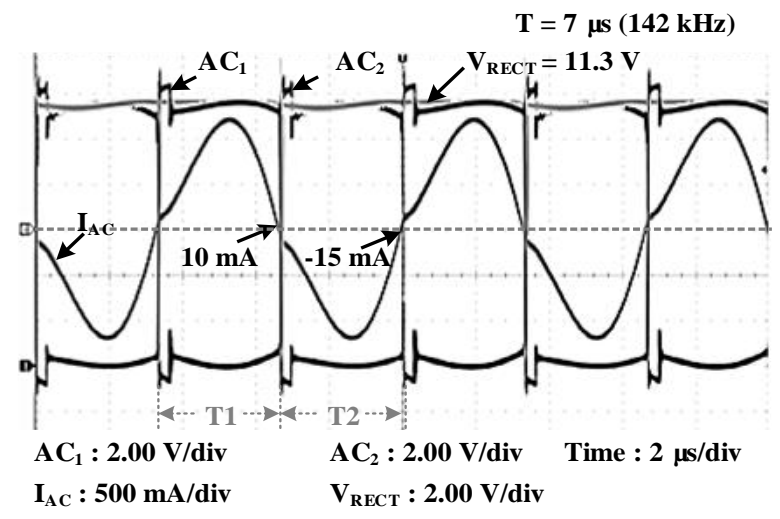

Figure 11. Measured waveform of the active rectifier.

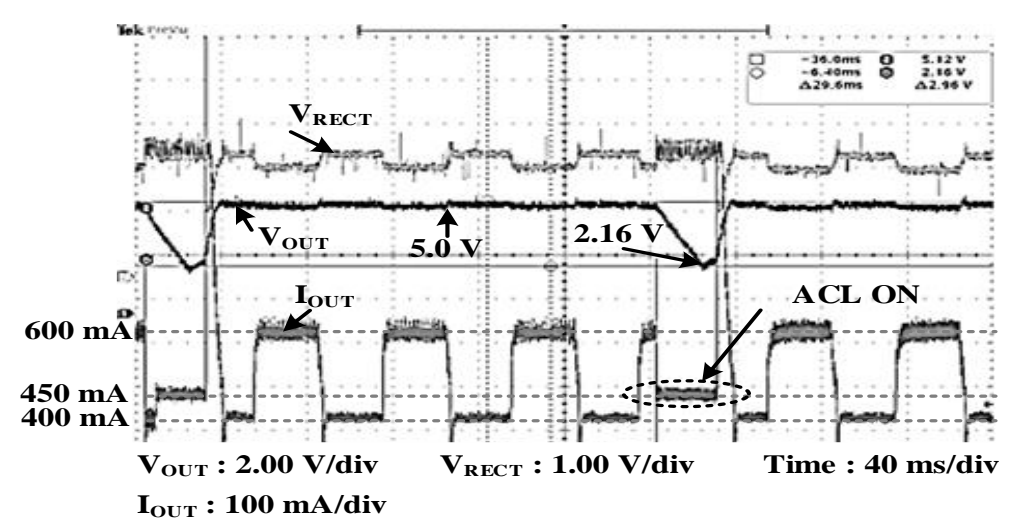

Figure 12. Measured waveform of multi-feedback LDO (MF-LDO).

In Figure 13, the rectifier output voltage $\left(\mathrm{V}_{\mathrm{RECT}}\right)$ can change from $6 \mathrm{~V}$ to $8 \mathrm{~V}$, whereas the variation of MF-LDO output voltage ( $\mathrm{V}_{\text {OUT }}$ ) is less than $89 \mathrm{mV} / \mathrm{A}$. For this measurement, $\mathrm{V}_{\mathrm{RECT}}$ is provided from the power supply.

When the value of load current is $800 \mathrm{~mA}$ in Figure 14, the maximum measured PCE of the active rectifier and wireless power receiver are $94.2 \%$ and $85.3 \%$, respectively.

The performance comparison with prior works is shown in Table $1[8,17,18]$. The examples from $[8,17]$ are active rectifiers for A4WP standard operating at $6.78 \mathrm{MHz}$ and their efficiencies are $91.5 \%$ and $94.2 \%$ 
respectively. The maximum efficiency of [18] is $92.7 \%$ when the input frequency is $150 \mathrm{kHz}$. Therefore, this work achieves an efficiency of $92.4 \%$ and has the best performance when the input frequency is $150 \mathrm{kHz}$. This work shows the highest overall efficiency of a rectifier compared with references.

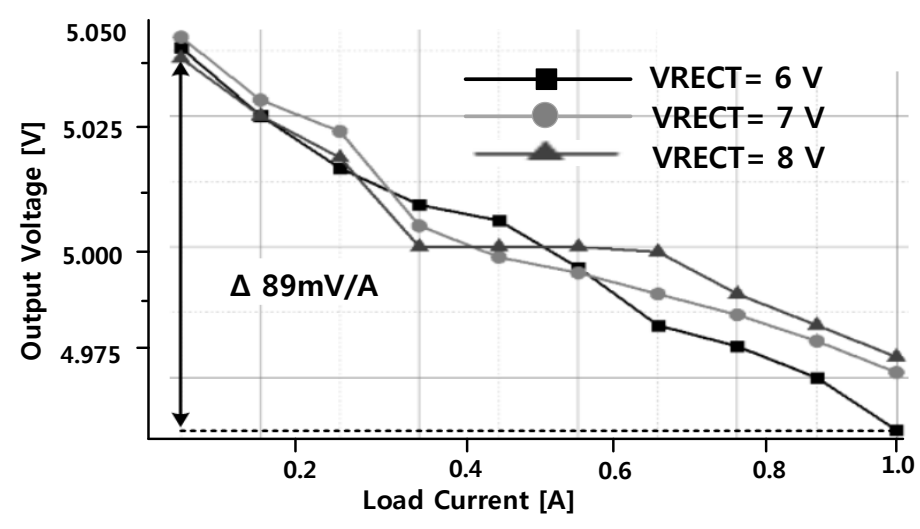

Figure 13. Measured output voltage of multi-feedback LDO (MF-LDO).

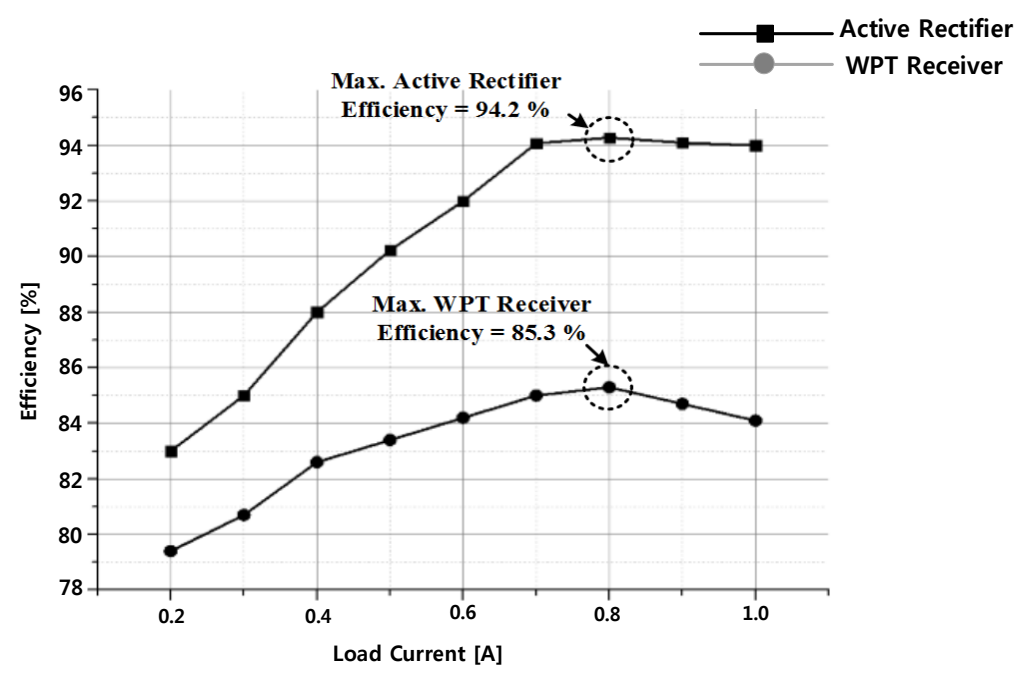

Figure 14. Measured PCE of the active rectifier and wireless power receiver.

Table 1. Performance comparison with prior works.

\begin{tabular}{|c|c|c|c|c|}
\hline Parameters & [8] & [17] & [18] & This Work \\
\hline Technology & $0.18 \mu \mathrm{m}$ BCD & $0.18 \mu \mathrm{m}$ CMOS & $0.18 \mu \mathrm{m} \mathrm{BCD}$ & $0.18 \mu \mathrm{m} \mathrm{BCD}$ \\
\hline Supported standards & A4WP & A4WP & WPC and PMA A4WP & WPC and PMA \\
\hline Input frequency & $6.78 \mathrm{MHz}$ & $6.78 \mathrm{MHz}$ & $\begin{array}{c}85 \mathrm{kHz} \sim 500 \mathrm{kHz} \\
6.78 \mathrm{MHz}\end{array}$ & $87 \mathrm{kHz} \sim 375 \mathrm{kHz}$ \\
\hline Input Voltage Range (V) & $7-20$ & $7-20$ & $3-20$ & $3-20$ \\
\hline Efficiency of rectifier (\%) & 91.5 & $\begin{array}{c}94.2 \\
\text { (rectifier only) }\end{array}$ & $\begin{array}{c}91.7 @ 6.78 \mathrm{MHz} \\
92.7 @ 150 \mathrm{kHz}\end{array}$ & $94.2 @ 150 \mathrm{kHz}$ \\
\hline Post-regulator & DC-DC converter & $\mathrm{N} / \mathrm{A}$ & DC-DC converter & $\begin{array}{l}\text { Low-dropout } \\
\text { regulator }\end{array}$ \\
\hline System efficiency (\%) & 80.86 & $\mathrm{~N} / \mathrm{A}$ & $\begin{array}{c}84.5 @ 6.78 \mathrm{MHz} \\
85.5 @ 150 \mathrm{kHz}\end{array}$ & 85.3 \\
\hline Max. output power (W) & 6 & 8 & 9 & 5 \\
\hline Die area $\left(\mathrm{mm}^{2}\right)$ & 12.25 & 3.45 & 17.5 & 16.0 \\
\hline
\end{tabular}




\section{Conclusions}

This work describes an inductive coupling (WPC/PMA) WPR having high-efficiency Active rectifier and MF-LDO Regulator. The synchronous Active rectifier with ZCS is proposed to get high efficiency in order to reduce the reverse leakage current. MF-LDO Regulator is proposed to implement the output voltage regulation, OVP, over current limit (OCL), and ACL sharing the single power transistor.

This chip is implemented in the $0.18 \mu \mathrm{m} \mathrm{BCD}$ technology having die area of $16.0 \mathrm{~mm}^{2}$. The maximum PCE of the Active rectifier is $94.2 \%$ at $800 \mathrm{~mA}$ load current.

Acknowledgments: This work was supported by Institute for Information \& Communications Technology Promotion (IITP) grant funded by the Korea government (MSIP) (No. B0717-16-0057, Development of MST integrated $15 \mathrm{~W}$ magnetic induction/resonance wireless charging technology). This work was supported by the National Research Foundation of Korea (NRF) grant funded by the Korean government(MSIP) (2014R1A5A1011478).

Author Contributions: Kang-Yoon Lee guided and directed the autors for this work. Zaffar Hayat Nawaz Khan and Young-Jun Park studied, proposed and designed the overall architecture of synchronous active rectifier and Multi Feedback low drop out (LDO) Regulator coupled with a wireless power receiver. They wrote the paper. Byeong Gi Jang, Seong-Mun Park and Hamed Abbasizadeh contributed in making the layout of the proposed architecture. Keum Cheol Hwang guided the antenna and measurments. Young Gun Pu performed the measurements with Zaffar, Young-Jun Park and Seong Jin Oh. Youngoo Yang and Minjae Lee designed the related top architecture.

Conflicts of Interest: The authors declare no conflict of interest.

\section{References}

1. Wireless Power Consortium System. Description Wireless Power Transfer, Vol. I: Low Power, Part 1: Interface Definition Version 1.0. July 2010. Available online: https:/ / www.wirelesspowerconsortium.com (accessed on 23 February 2018).

2. Kiani, M.; Lee, B.; Yeon, P.; Ghovanloo, M. A Q-modulation technique for efficient inductive power transmission. IEEE J. Solid-State Circuits 2015, 50, 2839-2848. [CrossRef] [PubMed]

3. Choi, J.-H.; Yeo, S.-K.; Park, S.; Lee, J.-S.; Cho, G.-H. Resonant regulating rectifiers (3R) operating for $6.78 \mathrm{MHz}$ resonant wireless power transfer (RWPT). IEEE J. Solid-State Circuits 2013, 48, 2989-3001. [CrossRef]

4. Moh, K.-G.; Neri, F.; Moon, S.; Yeon, P.; Yu, J.; Cheon, Y.; Roh, Y.; Ko, M.; Park, B.-H. A fully integrated 6W wireless power receiver operating at $6.78 \mathrm{MHz}$ with magnetic resonance coupling. In Proceedings of the 2015 IEEE International Solid-State Circuits Conference, San Francisco, CA, USA, 22-26 February 2015; IEEE: Piscataway, NJ, USA, 2015; pp. 230-231.

5. Cheng, L.; Ki, W.H.; Tsui, C.Y. A 6.78-MHz single-stage wireless power receiver with a 3-mode reconfigurable resonant regulating rectifier. IEEE J. Solid-State Circuits 2017, 52, 1412-1423. [CrossRef]

6. Koh, K.; Beh, T.; Imura, T.; Hori, Y. Impedance Matching and Power Division Using Impedance Inverter for Wireless Power Transfer via Magnetic Resonant Coupling. IEEE Trans. Ind. Appl. 2013, 50, 2061-2070. [CrossRef]

7. Hashemi, S.; Sawan, M.; Savania, Y. A Novel Fully-Integrated Drop Less Voltage CMOS Rectifier for Wireless Powered Devices. In Proceedings of the 2007 Internatonal Conference on Microelectronics, Cairo, Egypt, 29-31 December 2007; pp. 333-336.

8. Park, H.-G.; Jang, J.-H.; Kim, H.-J.; Park, Y.-J.; Oh, S.J.; Pu, Y.G.; Hwang, K.C.; Yang, Y.; Lee, K.-Y. A Design of a Wireless Power Receiving Unit With a High-Efficiency 6.78-MHz Active Rectifier Using Shared DLLs for Magnetic-Resonant A4 WP Applications. IEEE Trans. Power Electron. 2016, 31, 4484-4498. [CrossRef]

9. Guo, S.; Lee, H. An Efficiency-Enhanced CMOS Rectifier With Unbalanced-Biased Comparators for Transcutaneous-Powered High-Current Implants. IEEE J. Solid-State Circuits 2009, 44, 1796-7804. [CrossRef]

10. Lee, H.-M.; Ghovanloo, M. An Adaptive Reconfigurable Active Voltage Doubler/Rectifier for Extended-Range Inductive Power Transmission. IEEE Trans. Circuits Syst. II Express Briefs 2012, 59, 481-485. [CrossRef]

11. Lu, Y.; Ki, W.-H. A 13.56 MHz CMOS Active Rectifier with Switched-Offset and Compensated Biasing for Biomedical Wireless Power Transfer Systems. IEEE Trans. Biomed. Circuits Syst. 2013, 8, 334-344. 
12. Cheng, L.; Ki, W.H.; Lu, Y.; Yim, T.S. Adaptive on/off delay-compensated active rectifiers for wireless power transfer systems. IEEE J. Solid-State Circuits 2016, 51, 712-723.

13. Lam, Y.-H.; Ki, W.-H.; Tsui, C.-Y. Integrated Low-Loss CMOS Active Rectifier for Wirelessly Powered Devices. IEEE Trans. Circuits Syst. II: Express Briefs 2006, 53, 1378-1382. [CrossRef]

14. Tseng, R.; Novak, B.; Shevde, S.; Grajski, K.A. Introduction to the alliance for wireless power loosely-coupled wireless power transfer system specification version 1.0. In Proceedings of the 2013 IEEE Wireless Power Transfer (WPT), Perugia, Italy, 15-16 May 2013; pp. 79-83.

15. Park, Y.-J.; Oh, S.J.; Kim, S.Y.; Cho, S.; Kim, M.C.; Park, J.-H.; Lee, D.S.; Kim, H.J.; Lee, K.-Y. A Design of Inductive Coupling Wireless Power Receiver with High-Efficiency Active Rectifier and Multi Feedback LDO Regulator. In Proceedings of the 2016 IEEE Wireless Power Transfer Conference (WPTC), Aveiro, Portugal, 5-6 May 2016.

16. Shinohara, H.; Miyaji, K. A ZVS CMOS active diode rectifier with voltage-time-conversion delay-locked loop for wireless power transmission. In Proceedings of the 2015 IEEE Asian Solid-State Circuits Conference (A-SSCC), Xiamen, China, 9-11 November 2015; pp. 3-15.

17. Park, Y.-J.; Park, H.-G.; Lee, J.; Oh, S.J.; Jang, J.H.; Kim, S.Y.; Pu, Y.G.; Hwang, K.C.; Yang, Y.; Seo, M.; et al. A design of wide input range triple-mode active rectifier with peak efficiency of $94.2 \%$ and maximum output power of $8 \mathrm{~W}$ for wireless power receiver in $0.18 \mu \mathrm{M}$ BCD. Analog Integr. Circuits Signal Process. 2016, 86, 255-265. [CrossRef]

18. Park, Y.-J.; Jang, B.G.; Park, S.-M.; Ryu, H.-C.; Oh, S.J.; Kim, S.-Y.; Pu, Y.G.; Yoo, S.-S.; Hwang, K.C.; Yang, Y.; et al. A Triple-Mode Wireless Power Receiving Unit with 85.5\% System Efficiency for A4WP, WPC and PMA Applications. IEEE Trans. Power Electron. 2018, 33, 3141-3156. [CrossRef]

(C) 2018 by the authors. Licensee MDPI, Basel, Switzerland. This article is an open access article distributed under the terms and conditions of the Creative Commons Attribution (CC BY) license (http://creativecommons.org/licenses/by/4.0/). 